\title{
DESIGN OF A RECONFIGURABLE, MULTI-FREQUENCY \& CIRCULARLY POLARIZED MICROSTRIP PATCH ANTENNA
}

\author{
Mrigendra Pratap Singh ${ }^{1}$, Shivraj Singh ${ }^{2}$ \\ ${ }^{I}$ Research Scholar, ECE Department, Technocrats Institute of Technology, Bhopal, M.P., India \\ ${ }^{2}$ Asst. Professor, ECE Department, Technocrats Institute of Technology, Bhopal, M.P., India
}

\begin{abstract}
Abstract: In this microstrip antenna design multi frequencies are used. Here working frequencies are $1.9 \mathrm{GHz}$ and $2.0 \mathrm{GHz}$. Rectangular patch shape technique is used for designing this microstrip antenna. In our model electric field lines, conductance and input resistance have obtained by transmission line model whereas charge distribution, directivity and gains have brought by cavity model of rectangular patch. Correct feeds are applied at various positions and after comparing all the results the best of all will increase the efficiency and gain of microstrip patch antenna by 30-35\%. All the results are mathematically calculated and achieved but these results may also be obtained by various designing software like Zeland IE3D software, Ansoft's HFSS software and CST software.
\end{abstract}

Keywords: Cavity Model, Feeding Technique, Microstrip Antenna, Rectangular Patch and Transmission Line Model

\section{INTRODUCTION}

Since a very long time man had dreamt of transmitting signals from one place to another. In 1983 by Maxwell's equations electromagnetic waves are discovered which was successfully shown by Hertz in 1887 and presently lots of research was done in this field. There are several ways of communication but radio communication (wireless communication) is the most fascinating and popular system in radio communication presently.

European telecommunication standards institute (ETSI) define a standard set called "Global Systems for Mobile" (GSM) for second generation (2G) digital cellular network used by cellphones.GSM technology provide us various facilities like: network used by cellphones.GSM technology provide us various facilities like: network used by cellphones.GSM technology provide us various facilities like: network used by cellphones.GSM technology provide us various facilities like:

- Text massaging

- Internet service

- Call forwarding \& waiting

- $\quad$ Caller ID \& encrypted calling service.

In 1999-2000 GSM networks works on $900 \mathrm{MHz}$ frequency but nowadays continuously number of customers are increasing so that there is lack of frequency channels. To overcome this problem there are various methodologies are used:

1. Frequency reuse

2. Cell structure

3. Adding micro cells

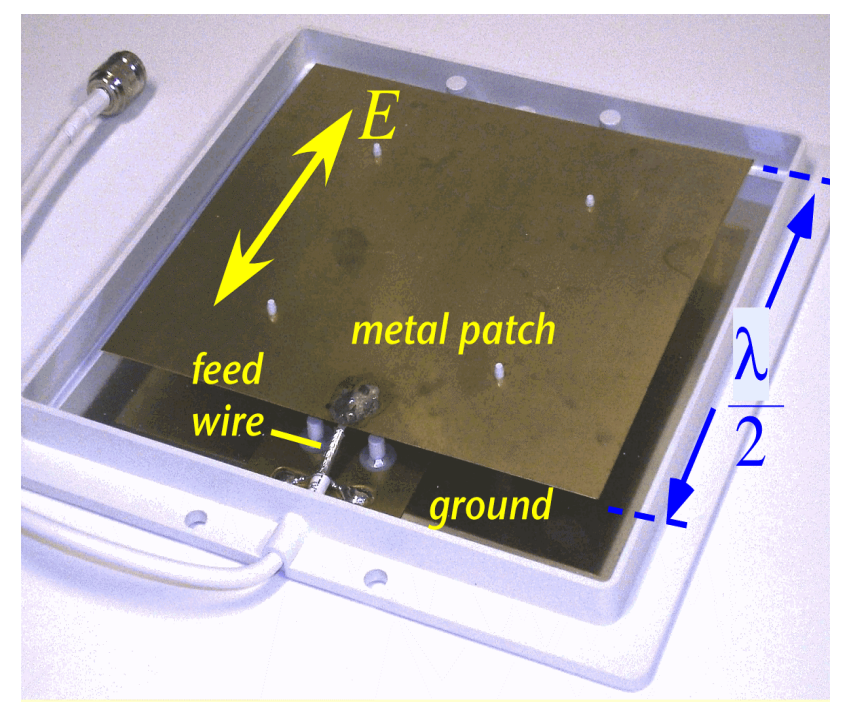

Fig -1: Microstrip Patch Antenna

All these methods are good but not sufficient enough for better performance we need to increase our frequencies. Presently $1.8 \mathrm{GHz}$ and $1.9 \mathrm{GHz}$ frequencies are introduced in GSM networks. In this paper I am proposing a Microstrip patch antenna which works on multi frequency $1.9 \mathrm{GHz}$ and 2.0 GHz respectively. Our design is reconfigurable and thin for that correct feed position is obtained by impedance matching. I am using IE3D software for simulating the frequency $1.9 \mathrm{GHz} \& 2.0 \mathrm{GHz}$.

\section{DESIGNS AND MEASUREMENT}

Microstrip antenna is useful in various applications because they are low profile, light in weight and very conformable to surface and having low manufacturing cost using printed circuit technology. For a rectangular Microstrip patch antenna, thicker substrate with low dielectric constant provides very good efficiency and larger bandwidth but size 
of the element will be increases means high expenses. Thin substrate and higher dielectric constant need small element size so that efficiency is less and bandwidth is also small.

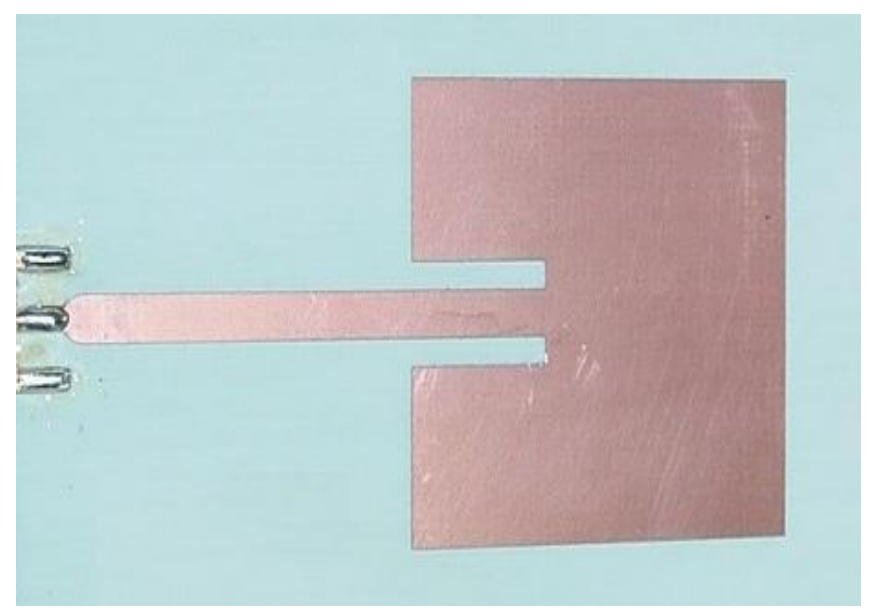

Fig -2: Top View of Rectangular Patch

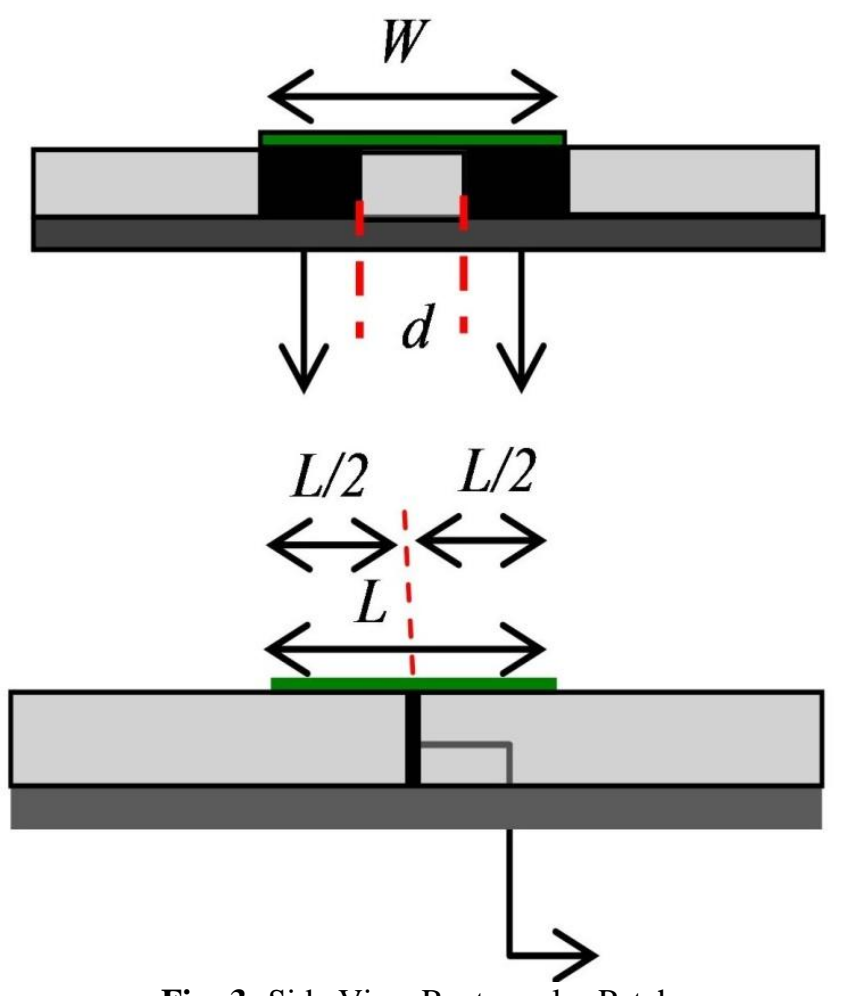

Fig -3: Side View Rectangular Patch

Due to fringing effect the effective electrical length of the patch is greater than the physical length i.e. $\mathrm{L}_{\text {eff }}>\mathrm{L}$ as shown in figure above.

\subsection{Feeding Technique}

There are various methods of feeding Microstrip patch antenna. It can be classified into categories:

$$
\begin{array}{cl}
\text { i. } & \text { Contacting } \\
\text { ii. } & \text { Non-contacting }
\end{array}
$$

In contacting method the RF power is feeding directly to the patching surface using a connector element example: SMA Connector. In second methodology electromagnetic field coupling transfers the power between the Microstrip line and patch.

Microstrip line feed technique has a conducting strip connected directly to Microstrip patch edge. Coaxial Feed is another but a very common technique of feeding. In this technique the inner conductor of the coaxial connector extends \& soldered with patch (radiating). Now the transmission line model is the simplest designed to construct a rectangular patch Microstrip antenna because a parallelplate transmission line connecting two radiating apertures having width $\mathrm{W}$ and height $\mathrm{h}$.
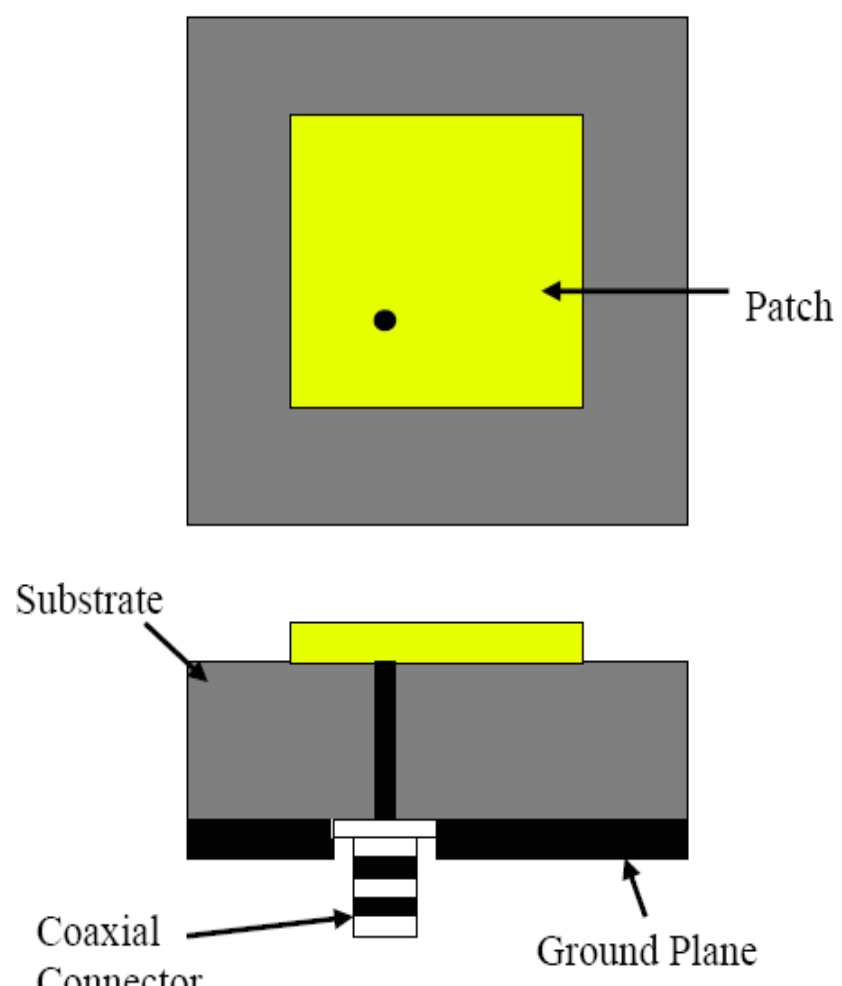

Fig -4: Microstrip Probe feeding

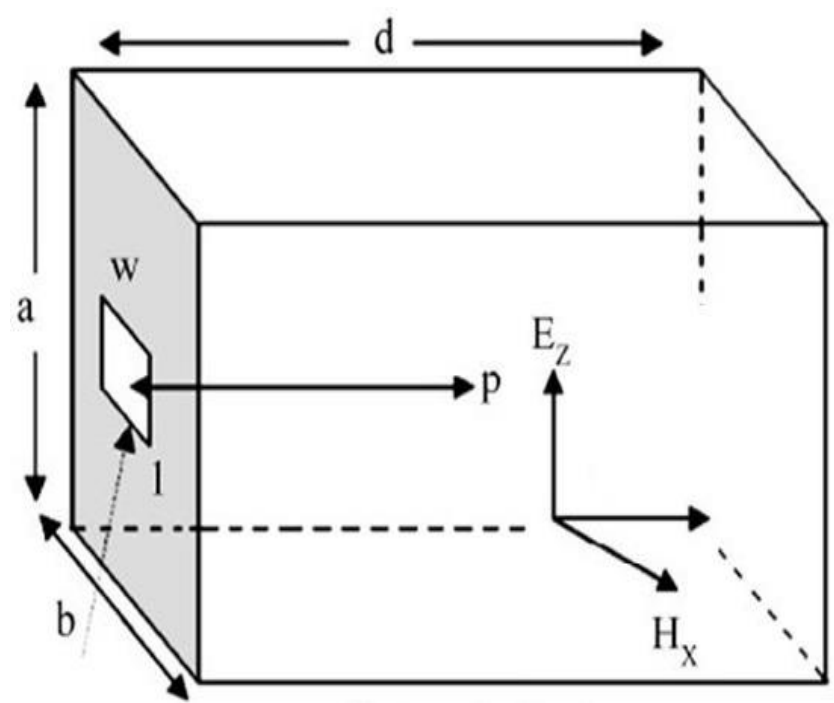

Fig -5: Rectangular Transmission Line Model 
In the above figure $\mathrm{Z}$ is the direction of propagation. Basically transmission line approach is not perfect due to low versatility but it provides a good physical insight into the nature of the rectangular antenna and field distribution for all TM modes.

The slot shows very high impedance from both sides of the transmission line so that we assume that this structure is having highly resonant characteristics which depend on its length $\mathrm{L}$ and propagation direction $\mathrm{Z}$. We know that $\mathrm{L}_{\text {eff. }}>L$ thus the resonance condition is $\beta(\mathrm{n}) \mathrm{L}_{\mathrm{eff}}>\mathrm{n} \cdot \mathrm{n}_{2}^{\pi}$ where, $\mathrm{n}=1,2, \ldots$, all depends upon $\mathrm{L}_{\text {eff., }}$ not on physical length L. so that effective patch length is

$$
\frac{\Delta \mathrm{L}}{\mathrm{h}}=0.412 \frac{\left(\varepsilon_{\text {reff }}+0.3\right)\left(\frac{\mathrm{W}}{\mathrm{h}}+0.264\right)}{\left(\varepsilon_{\text {reff }} \cdot-0.258\right)\left(\frac{\mathrm{W}}{\mathrm{h}}+0.8\right)} .
$$

For effective length $\mathrm{L}_{\text {eff. }}=\mathrm{L}+2 \Delta \mathrm{L}$.

So that Length of patch is

$$
\mathrm{L}=\frac{1}{2 \mathrm{f}_{\mathrm{r}} \sqrt{\varepsilon_{0} \mu_{0}} \sqrt{\varepsilon_{\text {reff }}}}-2 \Delta \mathrm{L}
$$

And resonant frequency for TM001 mode

$$
\mathrm{f}_{\mathrm{r}}=\frac{\mathrm{c}}{2 \mathrm{~L}_{\mathrm{eff}} \cdot \sqrt{\varepsilon_{\text {reff }}}}
$$

Antenna polarization is generally determined by three basic parameters:
i. Axial ratio
ii. Tilt angle
iii. Rotation

When axial ratio is zero then polarization is linear and quality of polarization depends upon the cross polarization for perfect circular polarization axial ratio should be one (unity). Microstrip patch is widely used radiators for circular polarization. There are basically two types of excitation technique for circular polarization in Microstrip patch antenna.

i. Dual fed patch

ii. Single fed patch

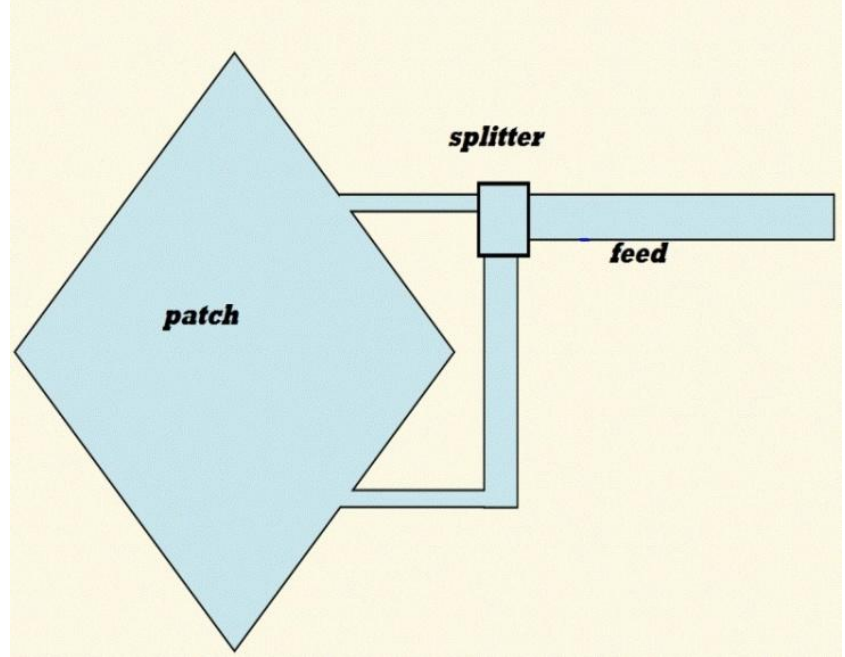

Fig -6: Dual Feed patching

A connector is connected at feed point it may be co-axial feed connector or SMA feed connector. In single fed patch there is less need of splitter where as in dual fed patch splitter is used.

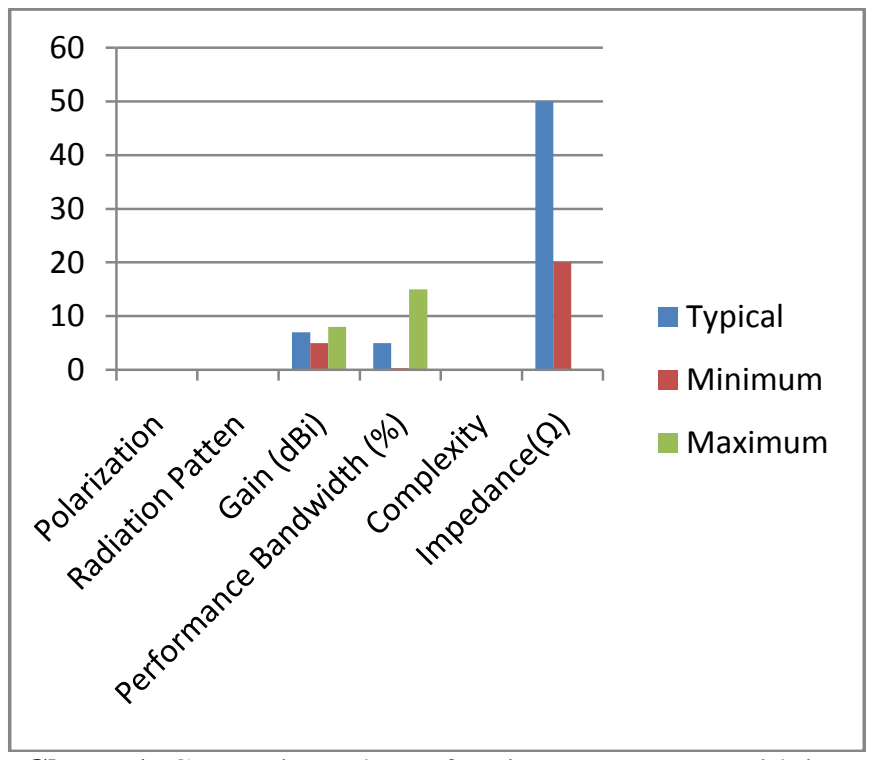

Chart -1: Comparison chart of various parameters with in microstrip patch antenna

Table -1: Quick Summary of Patch Antenna

\begin{tabular}{|l|l|l|l|}
\hline Quantity & Typical & Minimum & Maximum \\
\hline Polarization & linear & & \\
\hline $\begin{array}{l}\text { Radiation } \\
\text { Patten }\end{array}$ & $\begin{array}{l}\text { Single } \\
\text { broadside } \\
\text { lobe }\end{array}$ & 7 & 8 \\
\hline Gain (dBi) & 7 & 5 & 15 \\
\hline $\begin{array}{l}\text { Performance } \\
\text { Bandwidth } \\
(\%)\end{array}$ & 5 & 0.3 & \\
\hline Complexity & Moderate & $\mathbf{2 0}$ & $\approx \mathbf{3 0 0}$ \\
\hline Impedance( $\mathbf{\Omega})$ & $\mathbf{5 0}$ & $\mathbf{2}$ & \\
\hline
\end{tabular}


Dual circular polarization has also been achieved using a singly fed triangular or Pentagonal Microstrip antenna. The radiation efficiency will be $70 \%$. Once the dimensions are obtained the antenna can be simulated on a commercially available IE3D EM simulator. And further optimization and fine tuning of dimensions can be carried out to bring the resonance back at the desired frequency with acceptable return loss. Layout generation can be done in interlaced or AutoCAD software for preparing the mask. Once the mask is pointed on a transparent sheet, the patch can be fabricated using conventional photolithography process. The return loss for the patch antenna can be measured on a network Analyzer. The E-plane and H-plane patterns can be measured in a far-field test set up (preferably in an anechoic chamber) with a standard gain antenna as a transmitting antenna and the Antenna under test as a receiving antenna mounted on a pedestal.

\section{CONCLUSIONS}

Finally $2 \mathrm{G}$ spectrums $(900 \mathrm{MHz}-1800 \mathrm{MHz})$ and $3 \mathrm{G}$ (1800MHz-2000MHz) spectrums are used by old generation handset antenna but my proposed antenna design is capable of working in both frequencies weather its belongs to $2 \mathrm{G}$ or $3 \mathrm{G}$ spectrums simultaneously. My multi frequency antenna design is capable of handling two different frequencies simultaneously but in future advancement it's also possible to design an penta frequency (900MHz/1800MHz/1900MHz/ 2000MHz and $2200 \mathrm{MHz}$ ) operated antenna also.

\section{ACKNOWLEDGEMENTS}

I am heartily thanks to Technocrats Institute of Technology and Maulana Azad National Institute of Technology, Bhopal for helping me in my research work.

\section{REFERENCES}

[1]. Sheng Tu, Qingsha S. Cheng, Yifan Zhang, John W. Bandler, and Natalia K. Nikolova, "Space Mapping Optimization of Handset Antennas Exploiting Thin-Wire Models", IEEE Transactions On Antennas And Propagation, Vol. 61, No. 7, July 2013.

[2]. ArpitaSen, Prafulla Chandra Prasad, Neela Chattoraj,"Design and Development of a Single Feed Reconfigurable Dual-Frequency Microstrip Antenna", IEEE International conference on Communication and Signal Processing, April 3-5, 2013, India

[3]. Shaya Karimkashi and Guifu Zhang, "A Dual-Polarized Series-Fed Microstrip Antenna Array With Very High Polarization Purity for Weather Measurements", IEEE transactions on antennas and propagation, vol. 61, no. 10, October 2013

[4]. Amit A. Deshmukh, AporvaA. Joshi, Ankita R. jain, Tejal A. Tirodkar, and K. P. Ray, "Broadband Proximity fed half U-slot cut Rectangular Microstrip Antennas, "IEEE Third International Conference on Advances in Computing and Communications, June-2013.

[5]. Marija M. Nikolic', Antonije R. Djordjevic',and Arye Nehorai, "Microstrip Antennas With Suppressed Radiation in Horizontal Directions and Reduced Coupling", IEEE transactions on antennas and propagation, vol. 53, no. 11, November 2013.

[6]. Ehab K. I. Hamad and Ahmed H. Radwan, "B14. Compact Ultra Wideband Microstrip Fed Printed Monopole Antenna", $30^{\text {th }}$ NATIONAL RADIO SCIENCE CONFERENCE (NRSC 2013) April 16-18, 2013, National Telecommunication Institute, Egypt IEEE 2013

[7]. Fang-Yao Kuo, and Ruey-Bing Hwang, "High Isolation X-band Marine Radar Antenna Design”, IEEE 2013-14

[8]. M. Samsuzzaman, M. T. Islam, N .Misran, M.A. Mohd Al, "Dual band X shape Microstrip Patch Antenna for Satellite Applications", The 4th International Conference on Electrical Engineering and Informatics (ICEEI 2013), November-2013.

[9]. Lechen Yang, XueshunShi, KunfengChen, KaiFu, BaoshunZhang, "Analysis of photonic crystal and multifrequency terahertz microstrip patch antenna", Elsevier B.V. 31 August 2013

[10]. IEEE Transactions on Antenna and Propagation, vols. AP-17, No. 3, May 1969; AP-22, No. 1, January 1974; and AP-31, No. 6, Part 2, November 1983.

[11]. C. A. Balanis, Antenna Theory: Analysis and Design, 2nd ed., Wiley, 1997.

[12]. R. Garg, P. Bhartia, I. Bahl and A. Ittipiboon, Microstrip Antenna Design Handbook, Artech House, 2001. [13]. The Integration Of Rectangular SIW Filter and Microstrip Patch Antenna Based On Cascaded Approach by Z.Zakariaa, W.Y.Sama, M.Z.. Abdaziza and M.Muzafar Ismaila in Malaysian Technical Universities Conference on Engineering \& Technology 2012, MUCET 2012 published by Elsevier Ltd.

\section{BIOGRAPHIES}

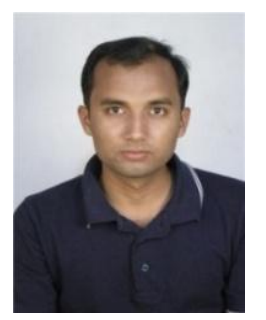

Mrigendra Pratap Singh received his Bachelor of Engineering in Electronics \& Communication Engineering from Rashtrasant Tukadoji Maharaj Nagpur University (Maharashtra) India in 2011 Presently he is doing his Master's degree in Electronics \& Communication Engineering from Technocrats Institute of Technology, Bhopal. His area of research is patch antenna and its propagation. He is active member of IEEE Madhya Pradesh Sub Section and IETE.

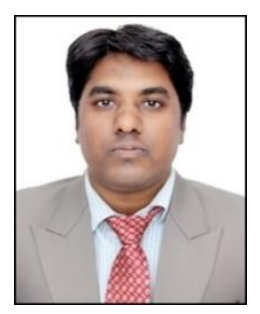

Prof. Shivraj Singh received his bachelor's degree in Electronics \& Communication engineering from Sagar Institute of Research \& Technology, Bhopal in 2007 and Master's degree in Digital Communication from Technocrats Institute of Technology, Bhopal in 2012. Presently he is working as an Assistant Professor in Technocrats Institute of Technology. His research interest is in the field of antenna and wireless communication. He published several papers in various research journals. 